\title{
Trajectória dos argumentos sobre as ações afirmativas: da marcha Zumbi dos Palmares à conferência de
}

\author{
durban
}

\author{
Viritiana Aparecida de Almeida ${ }^{121}$ \\ Nelson Rosário de Souza ${ }^{122}$
}

\section{RESUMO}

Este artigo tem como objeto de estudo a permanência e modificação de argumentos sobre as ações afirmativas. O objetivo é analisar tal permanência e modificação observando três momentos: a Marcha Zumbi dos Palmares, em 1995, - Seminário das Ações Afirmativas em Brasília, em 1996 e a Conferência de Durban, em 2001. Trata-se de estudo qualitativo sobre a fala de personagens importantes relacionados ao tema.

Palavras chaves: Ação Afirmativa. Disputa argumentativa. Racismo brasileiro.

\section{ABSTRACT}

This article has as its object of study the permanence and modification of arguments about affirmative action. The aim is to analyze such permanence and change watching three moments: the March Zumbi dos Palmares, in 1995, the Seminary of Affirmative Action in Brasilia in 1996 and the Durban Conference in 2001. It is a qualitative study on the speech of important characters related to the topic.

Keywords: Affirmative action. Argumentative dispute. Brazilian racism.

As ações afirmativas ${ }^{123}$ atraem a atenção de estudiosos brasileiros desde a luta do Movimento Negro Unificado - MNU pela implantação desta política. Entre

121 Mestranda em Ciência Política, UFPR, bolsista Capes

122 Doutor em Sociologia, USP, professor associado III da UFPR.

123 O termo ação afirmativa - também conhecido atualmente como discriminação positiva - indica o incentivo, por parte do Estado, para a inclusão social de grupos minoritários, percebidos como tais em face de traços estigmatizados como a raça, o gênero e a classe social. No princípio, o conceito não designava uma regra, antes buscava a conscientização da população para a existência de preconceito vigente na sociedade. Contemporaneamente as ações afirmativas são percebidas como arranjos legais de caráter provisório que visam instigar a igualdade substancial de indivíduos socialmente inferiorizados. O tratamento diferenciado para 
as correntes que reconhecem a desigualdade política e social associada à raça duas se destacam e alimentam o debate a respeito do tema. A diferença entre elas está no diagnóstico das causas desta desigualdade e, consequentemente, na postura frente à política pública de ações afirmativas. A primeira parte da ideia de que a desigualdade racial é fundamentalmente econômica (SOUZA, 2005). A segunda, de que a desigualdade resulta, principalmente, da discriminação racial (CAMPOS; DAFLON; FERES, 2010).

Observando o debate em foco o presente artigo procura: a) analisar como os argumentos a propósito das ações afirmativas apareceram no contexto da Marcha Zumbi dos Palmares, organizada pelo MNU no ano de 1995; b) verificar quais argumentos sobre raça, cultura e economia ganharam ênfase no seminário promovido pelo ex-presidente Fernando Henrique Cardoso (FHC) em Brasília, no ano de 1996; c) por fim, diagnosticar qual a trajetória dos principais argumentos mobilizados ao longo do tempo, comparando as justificativas apresentadas sobre as ações afirmativas nos três momentos em foco: a Marcha Zumbi dos Palmares (análise dos discursos sobre raça), o Seminário de 1996 (verificação dos discursos sobre raça, cultura e economia) e a Conferência de Durban (diagnóstico dos discursos sobre classe social e economia). Através de tais análises verificar-se-á se houve permanência ou modificação dos argumentos a respeito das ações afirmativas.

As Ciências Sociais têm valorizado as disputas argumentativas, a luta pela construção de justificativas plausíveis sobre o status quo, o funcionamento da sociedade, enfim, o 'espírito' do sistema vigente. Trata-se de um processo dinâmico, com incorporação de argumentos pelos adversários, reelaboração de significados e neutralização das críticas (BOLTANSKI e CHIAPELLO, 2009). Mostra-se válido adotar esta perspectiva para análise de um evento circunscrito, como as disputas argumentativas sobre a política de descriminação positiva em período recente.

os desiguais visa proporcionar aos grupos desfavorecidos a possibilidade de alcançar o mesmo status social que os demais componentes da comunidade (BELLINTANI, 2006). 
Parte-se da hipótese de que houve uma imbricação entre o argumento de que a desigualdade racial tem uma base cultural e aquele que remete a desigualdade racial a causas econômicas. Esta junção de linhas argumentativas gerou uma justificativa que tende a dissolver a questão da desigualdade e também da identidade racial, no caldo dos conflitos de classe social. $\mathrm{O}$ argumento baseado na raça, paradoxalmente, manteve a ênfase no biológico, ou seja, no aspecto genético, apesar de as teorias científicas terem negado este viés e do impulso inicial do movimento social na direção da desconstrução deste tipo de justificativa. A sobreposição de argumentos indica uma complexa combinação entre permanência, incorporação e mudança nas justificativas mobilizadas pelos críticos das ações afirmativas.

Para a comprovação da hipótese foi utilizado o método qualitativo análise de conteúdo (BAUER; GASKELL, 2002) - dos argumentos das ações afirmativas. O que foi feito mapeando o significado dos discursos de raça, classe social e economia presentes em artigos que tratam dos eventos da marcha Zumbi dos Palmares, Seminário em Brasília e da Conferência de Durban, a fim de diagnosticar possíveis alterações nas linhas argumentativas.

A alteração nos argumentos ocorreu de modo a desvalorizar certas justificativas em detrimento de outras. A justificativa apresentada na Marcha Zumbi dos Palmares, por exemplo, sofreu modificações cujo efeito foi prejudicial à luta por ações afirmativas.

\section{A MARCHA ZUMBI DOS PALMARES E SEUS ARGUMENTOS}

Os argumentos a respeito das discriminações positivas emergiram na Marcha Zumbi dos Palmares, organizada em 1995 pelo Movimento Negro Unificado - MNU. Tal passeata trouxe à cena pública justificativas de tipo racial, cultural e econômica. $O$ contexto era de avanço das lutas pelas políticas públicas de discriminação positiva. É possível observar a formulação de um contradiscurso referente à raça na Marcha Zumbi dos Palmares, pois o objetivo era desconstruir 
as teorias que trabalhavam o conceito de raça pelo viés biológico, presente nas correntes monogenista e poligenista. A primeira defendia que a humanidade era formada pelo gradiente que ia do menos ao mais perfeito. De acordo com tal vertente todos pertencem à mesma espécie, entretanto, a espécie comporta uma hierarquia entre as raças em função de supostas diferenças entre os níveis mentais. Ao passo que a teoria poligenista interpretava as raças como pertencentes a diferentes espécies, não redutíveis, portanto, a uma única humanidade.

A desconstrução desse conceito ancorou crítica à concepção de raça do Conde Gobineau, que via negros e índios como pertencentes a raças inferiores. Como apontaram Costa, Pinhel e Silveira (2012, p. 102), na "passagem da noção de raça degenerada de conde Gobineau para a celebração da cultura brasileira realizada por Gilberto Freyre na sua vasta obra, o sincretismo cultural termina servindo de modelo à mestiçagem entre famílias de origens étnicas e sociais distintas".

Observa-se que a Marcha Zumbi dos Palmares possibilitou uma contraposição ao argumento biológico sobre diferença racial. A ênfase passou para o lado da diferença cultural entre as raças. O discurso cultural deve seu impulso inicial na obra Casa grande e Senzala de Gilberto Freyre. Adeptos dessa visão partem da hipótese de que no Brasil o problema não é racial em termos biológicos, uma vez que, diferente de outras nações, nosso país sempre conviveu com a mestiçagem e a miscigenação.

A ideologia da mestiçagem e da miscigenação foi um constructo político incentivado pelo governo de Getúlio Vargas a fim de fundar a ideia de democracia racial moderna ${ }^{124}$. A miscigenação visava o branqueamento da população negra

124 A ideia de democracia racial traz à tona os discursos ideológicos da mestiçagem e da miscigenação, que servem à contestação das ações afirmativas para negros. " $O$ vocábulo 'democracia racial' foi usado pela primeira vez por Gilberto Freyre em 1962 com o intuito de atacar o conceito de 'negritude' cunhado por Aimé Cesaire, em 1937, que questionava o preconceito para com os negros. Para Gilberto Freyre os negros brasileiros estavam sofrendo influência de povos estrangeiros ao questionar as práticas de preconceito racial e por isso era seu dever opor-se 'à mística da 'negritude' como ao mito da 'branquitude': dois extremos sectários que contrariam a já brasileiríssima prática da democracia racial através da 
brasileira (COSTA, 2001). De acordo com tal política em aproximadamente três décadas a raça negra seria extinta, uma vez que os casamentos inter-raciais produziriam, com o passar dos anos, um fenótipo ${ }^{125}$ predominantemente branco (ROCHA, 2009). Em complemento à miscigenação a ideia de mestiçagem correspondia ao sincretismo cultural, que era base do projeto de construção de uma cultura brasileira unificada (COSTA, PINHEL; SILVEIRA, 2012) e universal.

$O$ argumento da mestiçagem e da miscigenação fortalece o discurso de que o problema racial no Brasil tem uma causa econômica; no limite, não seria um problema de conflito entre raças, mas, de classe, ou conflito entre classes. Segundo Jessé Souza (2005) os negros e os brancos pobres não conseguiram interiorizar os valores morais que emergiram na era moderna, demonstrando ser a variável explicativa da desigualdade histórica econômica, e não racial. Esse fato revela o processo de exclusão social dos brasileiros pobres de modo geral, independente da cor. E demonstra a necessidade de políticas públicas que reduzam a distância social entre pobres e ricos no acesso aos bens simbólicos que permitam a consolidação do projeto da nação moderna brasileira.

O discurso sobre a desigualdade racial pelo viés econômico motivou FHC a patrocinar um seminário para discutir tal problemática.

\section{ARGUMENTOS SALIENTES NO SEMINÁRIO DE BRASÍLIA}

$\mathrm{Na}$ Marcha Zumbi dos Palmares foi entregue ao ex-presidente FHC um documento oficial reivindicando a implantação de políticas de discriminação positiva:

Incorporar o quesito cor em diversos sistemas de informação; estabelecer incentivos fiscais às empresas que adotarem os programas de promoção da igualdade racial; instalar no âmbito do Ministério do Trabalho, a

mestiçagem: uma prática que nos impõe deveres de particular solidariedade com outros povos mestiços" (GUIMARAES, 2001, p. 7).

125 Fenótipo refere-se à aparência, às características manifestas de um organismo, incluindo traços anatômicos e psicológicos, que resultam tanto da hereditariedade quanto do ambiente. (EDUCAFRO, 2003) 
câmara Permanente de Promoção da Igualdade que deverá se ocupar de diagnósticos e proposições de políticas de igualdade no trabalho; implementar a convenção sobre Eliminação da Discriminação Racial no Ensino; conceber bolsas remuneradas a adolescentes negros de baixa renda, para o acesso e conclusão do primeiro e segundo graus; desenvolver ações afirmativas para acesso de negros em cursos profissionalizantes, as universidade e às áreas de tecnologia de ponta; assegurar a representação proporcional dos grupos étnicos raciais nas campanhas de comunicação do governo e de entidades que com eles mantenham relações econômicas (MOEHLECKE, 2002, p. 205 - 206).

A demanda pelas políticas de discriminação positiva da Marcha Zumbi dos Palmares levou FHC a reconhecer em 1995 o problema público do preconceito racial brasileiro. Ao reconhecer tal problema o governo levou em consideração os trabalhos acadêmicos patrocinados pelo próprio Estado, no ano de 1988, sobre a desigualdade histórica, com justificativas distribuídas entre os temas de raça, cultura e economia. $O$ então presidente também se comprometeu a realizar um seminário em Brasília no ano seguinte para debater o problema do preconceito contra os negros.

$\mathrm{Na}$ época da Assembleia Constituinte, em 1988, o governo valorizou as teses acadêmicas sobre negritude que focavam a desigualdade histórica. Os grupos de trabalhos (GTs) e mesas redondas (MRs) sobre questão racial se restringiram a temas sobre abolição e cultura negra, com o foco na desigualdade racial a partir do argumento econômico. As justificativas, portanto, não serviam de suporte às ações afirmativas, pois, negligenciavam a construção e/ou fortalecimento da identidade negra.

A referência à cultura negra exprimiu a contribuição dos costumes africanos na formação da nação brasileira, ou seja, na elaboração do ideal de cidadania universal. Em contrapartida, os discursos sobre abolição remetiam aos processos da assinatura da Lei Áurea. A escravidão foi apontada nos eventos como o fator principal na explicação da desigualdade histórica na sociedade brasileira. Quando os GTs e MRs indicaram a escravidão como fator explicativo da desigualdade histórica, favoreceram a emergência do argumento de que os negros sofrem preconceito não diretamente por causa das características fenotípicas, e sim pela dificuldade em incorporar para si à visão de mundo e os 
valores morais concernentes à era moderna (SOUZA, 2005). Como se vê, mais uma vez a causa fundamental da desigualdade entre as raças é instalada na dimensão da luta econômica e cultural entre as classes.

Nesse sentido, o argumento que enfatiza o preconceito fenótipo, ou seja, o preconceito racial - que a nosso ver, antecede e explica a desigualdade econômica brasileira - esteve sub-representado nos debates acadêmicos. Ao passo que as justificativas sobre desigualdade histórica vinculada ao viés da escravidão foram enfatizados por FHC no seminário realizado em Brasília em 1996. É importante insistir que este argumento sublinha a falta de preparo dos negros para ocupar os cargos vigentes na sociedade capitalista moderna.

O Seminário sobre ações afirmativas sediado na Universidade de Brasília - UNB teve como bibliografia principal as obras de Roberto DaMatta, Antonio Sergio Guimarães e Gilberto Freyre. Fernando Henrique Cardoso estava presente no evento e abriu a mesa de discussão fazendo um apelo à intelectualidade brasileira para ser criativa na busca de soluções para o problema da desigualdade histórica do Brasil. Segundo o Presidente da República à época, o Brasil tinha um caso particular de desigualdade histórica, incomparável com as experiências de preconceito norte-americano e sul-africano (GRIN, 2001). Por isso era inconcebível importar o modelo de ação afirmativa implantado nos EUA e forçar sua introdução no contexto social brasileiro. Para apoiar seu discurso FHC utilizou as obras de Roberto DaMatta e Gilberto Freyre.

Da primeira obra retirou o argumento de que no Brasil o preconceito pode ser traduzido na figura de uma pirâmide social. Ou seja, quanto mais próximo do estereótipo europeu, do fenótipo branco, quanto mais miscigenado, maior a chance de ascensão social que tem o afro-brasileiro (DAMATTA, 1981). Por isso, a discriminação racial no Brasil, segundo esta linha de argumentação, não seria um obstáculo significativo, ao contrário do que ocorre nos Estados Unidos da América. Nos EUA diz-se ocorrer o chamado preconceito de origem, enquanto nos trópicos ocorre o de marca. Onde existe o preconceito de marca, há uma preterição do indivíduo de cor negra, que sempre se vê em desvantagem frente a 
um indivíduo de cor branca nas mesmas condições; enquanto o preconceito de origem traz consigo a crença de que as características negativas da raça são hereditárias, transmitidas pelo sangue, o que gera um ódio entre brancos e não brancos.

Fernando Henrique Cardoso defendeu que a legislação norte-americana responde a uma situação de segregação racial, fato em tese ausente no Brasil, uma vez que o preconceito na América do Sul seria de marca. Por esse motivo não se deveriam implementar ações afirmativas baseadas em leis segregacionistas. Para fortalecer tal linha de argumentação FHC recorreu a justificativas presentes no clássico Casa Grande e Senzala, de Gilberto Freyre, afirmando que a difusão da ideologia da mestiçagem e da miscigenação produziu uma identidade racial brasileira harmoniosa. Engendrando a argumentação da ideologia da mestiçagem FHC citou dados estatísticos de pesquisas de opinião pública que, segundo ele, revelavam que os brasileiros reconheciam o preconceito contra os negros, mas mesmo assim defendiam a ideologia da mestiçagem. Depois de apresentar os dados estatísticos, FHC argumentou sobre o problema da desigualdade racial histórica pelo viés econômico e moderno.

Segundo FHC o problema da desigualdade racial histórica na nação brasileira seria um resquício da dicotomia entre povos atrasados e povos civilizados (GRIN, 2001). A cor da pele não seria uma barreira intransponível à ascensão social e, conforme o ex-presidente, a desigualdade racial desapareceria à medida que a nação brasileira se modernizasse. É possível traçar um paralelo entre a linha argumentativa de FHC, focada na modernização, e as justificativas mobilizadas pelo ex-presidente Getúlio Vargas. As duas abordagens pode ser consideradas conservadoras se considerarmos ser a construção da identidade negra etapa fundamental para conquista de direitos. Vargas baseou seus argumentos na purificação étnica, objetivo explícito das políticas de mestiçagem e miscigenação, uma vez que o negro era visto como um empecilho ao progresso nacional. FHC requentou as justificativas da era Vargas ao imaginar uma 'dissolução do problema racial' a partir do avanço econômico. 
$\mathrm{O}$ argumento de FHC expressa adesão ao ideal da mestiçagem, pois as barreiras na relação entre negros e brancos seriam superadas não pela luta por direitos, mas pela paulatina extinção da condição negra, o que permitiria o progresso brasileiro com benefícios para todos. O discurso de FHC sobre a modernização, ancorado na ideia da desigualdade racial histórica, também se assemelha aos discursos teóricos de Jessé Souza, discutido anteriormente, e de Florestan Fernandes.

$\mathrm{Na}$ sua rota de argumentação, com ênfase na modernização econômica, FHC buscou apoio na obra de Florestan Fernandes. Seu intento foi reforçar as justificativas ligadas à suposta desigualdade racial de raízes exclusivamente históricas e econômicas. Utilizando argumentos do livro "Integração do negro na sociedade de classe", de Florestan Fernandes, FHC afirma que o problema brasileiro é econômico. Ao apropriar-se dessa literatura para explicitar o problema da nação moderna no sentido econômico e cultural, o ex-presidente reforçou os alicerces conservadores do debate. Segundo FHC, Florestan Fernandes reconheceu a desvantagem do negro na engenharia da ideologia da mestiçagem, quando detectou três problemas que impediram a integração do escravo recémliberto à sociedade moderna: a) herança psicossocial do negro do regime escravocrata; b) o racismo praticado pelos imigrantes brancos brasileiros; e c) a falta de políticas governamentais voltadas à introdução do escravo recém-liberto na nova lógica do mercado de trabalho (GRIN, 2001).

O aspecto revelador desta linha argumentativa é que o primeiro fator, acima apresentado, acarreta os outros dois fenômenos, ou seja, a variável explicativa do processo está na suposição de que os negros não tinham condições psicológicas para assumir um papel na modernização, tampouco, cargos de comando. As justificativas operam um círculo vicioso: os negros não foram educados para desempenhar determinadas funções na sociedade moderna, ou melhor, eram sempre treinados para o desempenho de atividades subalternas, pois, o diagnóstico da herança psicossocial barrava esta política que, por sua vez, reproduzia a herança maldita. Foi tal argumentação tautológica que levou o 
governo Vargas a incentivar a vinda de milhares de imigrantes para ocupar os postos de trabalho emergentes no mercado brasileiro. Como educar o negro para os trabalhos industriais se, apesar de mão de obra livre, permanecia preso a uma herança maldita?

A tautologia argumentativa presente no discurso de FHC exprime uma posição conservadora recorrente na história do Brasil e remonta às políticas públicas de mestiçagem e miscigenação. $\mathrm{O}$ diagnóstico até aqui exposto reforça a tese de Hansebald segundo a qual a modernização econômica brasileira jamais colocaria fim ao preconceito racial vigente no Brasil (CAMPOS; DAFLON; FERES, 2010), pois, não é possível combater o que não é visto, ou o que não se quer enxergar.

Os argumentos de FHC encontraram resistências no próprio Seminário de Brasília. O cientista social Antonio Sergio Guimarães criticou as justificativas de FHC (GRIN, 2001). Guimarães defendeu a importância da implantação de ações afirmativas fundadas no critério racial. Para esse autor, as ações afirmativas fundadas no critério racial são a única via pela qual a desigualdade racial no mercado de trabalho, nas escolas e na publicidade pode ser reduzida. Para ele essas políticas não produziriam a segregação racial entre negros e brancos como nos EUA, ao contrário, elas permitiriam aos afro-brasileiros reconhecer sua identidade racial negra (GRIN, 2001). O reconhecimento da identidade negra possibilitaria a desconstrução do mito da democracia racial pautada na mestiçagem e miscigenação.

A desconstrução do mito da democracia racial, segundo os argumentos de Guimarães, engendraria a modernização do Brasil defendida por FHC. Contudo, tal tarefa exigiria, num primeiro momento, a "conciliação das fronteiras entre raça e classe social, diluindo a primeira na segunda, e num segundo momento a conciliação entre raça e cultura criando categorias classificatórias rígidas" (GRIN, 2001, p.185). Nesse sentido ele argumentou que a primeira iniciativa para possibilitar a consciência racial negra no Brasil já foi engendrada com a emergência do discurso do militante do MNU Abdias do Nascimento, que 
relacionou classe e raça e questionou a ideologia da mestiçagem. $O$ segundo passo está sendo dado com a imbricação dos discursos entre raça e cultura, que traz a cena o argumento da diversidade e coloca o negro como sujeito que reivindica ao Estado direitos para manter-se frente aos brancos (GRIN, 2006). Isso legitima as reivindicações por políticas de ações afirmativas específicas para negros e deságua na argumentação de que o preconceito racial não se compara a outros tipos de discriminação.

Antonio Sergio Guimarães não acredita na visão de FHC de que o preconceito de marca desaparecerá no processo de modernização da sociedade brasileira, pelo contrário, defende que a modernização acontecerá quando houver a desconstrução da ideia de harmonia racial presente na linha argumentativa filiada à tese da mestiçagem e da miscigenação. Desta perspectiva Guimarães reafirmou sua posição favorável à implantação de políticas de ações afirmativas fundadas no critério racial. Para ele o preconceito racial impede os discriminados de ascender socialmente (GRIN, 2001).

O contra-ataque aos argumentos de Antonio Sergio Guimarães vieram, no mesmo Seminário, pela voz do antropólogo Roberto DaMatta, que mobilizou justificativas semelhantes às usadas por FHC. $O$ antropólogo afirmou, por exemplo, que as "pessoas ficam brancas ou negras de acordo com suas atitudes, sucesso e, sobretudo, relacionamento" (GRIN, 2001, p.188). O argumento de DaMatta se aproxima do discurso de $\mathrm{FHC}$, quando este afirma que o preconceito racial desaparecerá à medida que a sociedade brasileira se modernizar. Ambas as falas compartilham o argumento segundo o qual o preconceito racial vigente no Brasil não é uma barreira intransponível, em oposição ao fenômeno que ocorre nos EUA. Por isso, ambos defendem a concretização do ideário da democracia racial brasileira. Para eles a opinião pública deseja ver concretizado esse ideal, como demonstrariam os dados estatísticos das pesquisas de opinião. $E$ nesse sentido, defendem a implantação de ações afirmativas, contanto que essas discriminações positivas não sejam uma cópia das experiências do sistema norte americano. FHC e DaMatta acreditam que a importação do modelo de ação 
afirmativa vigente nos EUA poderia produzir a divisão racial entre brancos e não brancos, fato ausente no Brasil até o momento devido à posição mediadora do mestiço brasileiro.

\section{CONFERÊNCIA DE DURBAN - PERMANENCIAS E MUDANÇAS}

O problema das desigualdades de gênero, de classe e étnico é mundial e assola as democracias contemporâneas. Tanto que se tornou uma das preocupações de agenda da Organização das Nações Unidas - ONU. O problema específico do racismo e da discriminação racial já vinha sendo discutido a portas fechadas pela ONU desde 1978. Esses debates eram realizados nos bastidores para não atrair a atenção dos meios de comunicação de massa em face do problema do apartheid ocorrido na África do Sul. Entretanto, com a posse do presidente civil negro Nelson Mandela, o problema da divisão racial entre brancos e negros neste país tomou novos rumos, favorecendo a discussão sobre a desigualdade histórica racial e econômica no mundo globalizado.

O debate sobre desigualdade racial histórica brasileira no âmbito internacional teve início com as denúncias dos movimentos negros à Organização Internacional do Trabalho - OIT contra a falta de iniciativa dos Estados referente às políticas contra a discriminação (MOEHLECKE, 2002). Isso impulsionou o reconhecimento mundial do problema do preconceito racial brasileiro. Aumentaram, assim, as pressões para a realização de uma conferência contra as diversas formas de discriminação existentes no mundo. A subcomissão do órgão de promoção e proteção dos 'Direitos Humanos' dentro da ONU lançou a proposta de uma conferência para tratar das diversas formas de discriminação. Desse órgão "emergiu, portanto, a resolução 1994/2 denominada Conferência mundial contra o racismo, discriminação racial ou étnica, a xenofobia e outras formas contemporâneas correlatas de intolerância" (ALVES, 2002, p. 202). A Conferência foi marcada para 2001 na cidade de Durban, na África do Sul. 
$\mathrm{Na}$ Conferência de Durban o debate sobre desigualdade racial histórica e econômica fez menção ao problema da desigualdade entre brancos e não brancos nos âmbitos escolar, da saúde e da habitação (CARNEIRO, 2002). Os discursos proferidos na conferência revelaram uma mistura entre os argumentos focados na economia e no âmbito cultural. Mistura essa que parece ter ancorado o argumento de classe social com viés econômico. Essa linha de justificativa parte da premissa de que o problema da desigualdade brasileira é de ordem social, portanto, se o governo investir na questão econômica, promoverá a democracia racial brasileira. Discurso semelhante ao de Fernando Henrique Cardoso no Seminário de Brasília. Ficou expressa a hegemonia dessa linha argumentativa. A desigualdade econômica a partir da conferência de Durban passou a ser interpretada como um dos "fatores que contribuem para as desigualdades sociais e econômicas duradouras em muitas partes do mundo de hoje" (ALVES, 2002, p. 212). O que demonstra que o fator econômico delimita a fronteira entre brancos e não brancos na busca pela igualdade material. Nesse sentido observa-se que a hipótese de Jessé Souza (2005) de que a fonte da desigualdade brasileira é econômica, dialoga com os discursos sustentados na Conferência de Durban.

O discurso baseado na desigualdade de classe levou os povos africanos a não conseguirem apoio para os pedidos de indenização e de perdão dos povos ocidentais pela prática da escravidão negra. Os Estados ocidentais se recusaram a aceitar tais demandas, o que provocou tensão no evento.

Foi retirada do documento final da Conferência a expressão "ação afirmativa" na fomentação da igualdade material, por mais que as associações negras, inclusive as brasileiras, as reivindicassem (ALVES, 2002). A exclusão de tal termo foi defendida pelos Estados Unidos e seus aliados, que temiam que a defesa dessa política se alastrasse no mundo globalizado. Além da retirada do vocábulo também foi abolido o uso do termo raça. A extinção desta palavra buscou afirmar que raças não existem e que por isso não há necessidade de se implementar políticas fundamentadas nessa crença. Argumento semelhante ao do geneticista Sergio Danilo Pena, precursor do manifesto intelectual contra as 
políticas de ações afirmativas que foi entregue ao Congresso Nacional no ano de 2006. Sergio Pena afirma que todos os brasileiros têm no seu genoma a contribuição dos três povos formadores da nação brasileira. Reencontramos o argumento central da ideologia da miscigenação, discutida neste trabalho, segundo o qual não tem como definir quem é negro ou branco fenotipicamente.

Numa entrevista dada a mídia televisiva, Sergio Danilo Pena afirmou que:

Raças não existem, cores de pele existem, mas são coisas diferentes e não devem ser confundidas nem misturadas em nenhum tipo de discurso. Praticamente todos os brasileiros têm as três raízes ancestrais presentes no seu genoma. (Sérgio Danilo Pena, notícia publicada pelo Jornal Nacional no dia 05 de março de 2010).

Ao mencionar as três raízes ancestrais o geneticista reforça o discurso da democracia racial através da prática da mestiçagem e miscigenação incentivada pelo governo de Getúlio Vargas. Sergio Pena, ao enfatizar o argumento da mestiçagem e miscigenação, defende que raças não existem, buscando amenizar o preconceito, visto que a mestiçagem é a prova da harmonia entre as raças (ACEVEDO; NONHARA, 2008).

Percebe-se que Sergio Pena não problematiza 0 conceito de miscigenação, que foi uma estratégia de purificação de raça - importante ressaltar que o termo raça foi discutido no século XIX com argumento científico de inferioridade da raça negra em relação à raça branca, como atestam as teses monogenista e poligenista. Ao contrário, preferiu argumentar que atualmente foi comprovado cientificamente que raças, no sentido biológico, não existem e que o problema da desigualdade racial histórica é um tema do pretérito, porque atualmente vigora no Brasil um povo mestiço. Por esse motivo as políticas de discriminação positiva devem levar em consideração a desigualdade econômica do país e o sofrimento da população brasileira de modo geral (MOYA; SILVERIO, 2009). Ao defender que a desigualdade histórica no Brasil engloba diversos segmentos da sociedade, Sergio Pena enfatiza a ideia de mestiçagem e miscigenação e minimiza o discurso da desigualdade contra o negro. 
Observa-se que a linha argumentativa sobre raça na Conferência de Durban manteve princípios da teoria monogenista e poligenista, além de acrescentar fatores genéticos para desconstruir os discursos sobre ações afirmativas vigentes na Marcha Zumbi dos Palmares.

O termo ação afirmativa, na Conferência de Durban, foi visto pelo ângulo das discriminações de gênero, racial e, sobretudo, econômica e social. Tal fato levou à reação de órgãos internacionais, que passaram a exigir dos Estados a criação de meios que permitam aos discriminados de modo geral a ascensão social. Essas exigências se encontram no artigo 108 do documento internacional:

\begin{abstract}
Medidas especiais para lograr representação apropriada nas instituições de ensino, na moradia, nos partidos políticos, nos parlamentos e no emprego, em particular em órgãos judiciais e policiais, no exército e outros serviços civis, o que, em alguns casos pode exigir reformas eleitorais, reformas agrárias e campanhas em prol da participação equitativa (ALVES, 2002, p. 215).
\end{abstract}

Tal artigo, ao reconhecer o problema das desigualdades, sobretudo pelo viés econômico, como revela a citação acima, abriu brecha para que os movimentos negros brasileiros reivindicassem ainda mais políticas de correção da desigualdade racial histórica, uma vez que o reconhecimento do artigo acima mencionado dificultava a luta dos movimentos negros pela política de ações afirmativas. Assim, a Conferência de Durban consolidou na agenda política brasileira a implementação de ações afirmativas, as quais ocorreram com o apoio, dentre outros, dos governos de Anthony Garotinho, Luis Inácio Lula da Silva, Ciro Gomes e José Serra.

Em 2003 o governo federal ampliou o debate das discriminações positivas em decorrência das negociações entre o governo, os movimentos sociais negros e os políticos profissionais afrodescendentes aliados ao Partido dos Trabalhadores (NASCIMENTO, 2007). Nessas negociações o viés de classe social pelo ângulo econômico sobressaiu mais uma vez, quando a maior parcela das instituições superiores de ensino aderiu o sistema de cotas sociais para alunos oriundos da escola pública. As cotas sociais são aceitas pela maior parcela das instituições, 
enquanto que a cota para negros ainda encontra grandes desafios. Tanto que no ano de 2010 o Partido Democrata - DEM impetrou o instrumento jurídico 'arguição de descumprimento do preceito fundamental ${ }^{126}$ - ADPF 186 - contra o Conselho de Ensino, Pesquisa e Extensão da Universidade de Brasília - UNB, que aderiu ao sistema de ações afirmativas com recorte étnico-racial. Além da ADPF-186 também foi interposto um recurso extraordinário ${ }^{127}$ (RE) por um estudante da Universidade Federal do Rio Grande do Sul (UFRGS) que se sentiu prejudicado pelo sistema de cotas sociais (COSTA; PINHEL; SILVEIRA, 2012).

Em ambos os casos citados há o pedido de declaração de inconstitucionalidade ${ }^{128}$ das ações afirmativas. Esse fato levou o Supremo Tribunal Federal - STF a realizar, no período de três a cinco de março de 2010, uma audiência pública - AP com especialistas no assunto das políticas de discriminações positivas a fim de julgar a ADPF 186 e o RE.

No debate das ações afirmativas na audiência pública a maior parcela dos especialistas defendeu a constitucionalidade das cotas sociais e raciais, mas a mídia brasileira se posicionou contrária às cotas raciais e favorável as cotas sociais com viés econômico (ALMEIDA, 2012). Tal como apareceu na Conferência de Durban.

\section{CONSIDERAÇÕES FINAIS}

126 Lei n 9.882/99, art. 10: "A arguição prevista no $\S 1^{\circ}$ do art. 102 da Constituição Federal será proposta perante o Supremo Tribunal Federal, e terá por objeto evitar ou reparar lesão a preceito fundamental, resultante de ato do Poder Público".

127 Constituição Federal, art. 102. "Compete ao Supremo Tribunal Federal, precipuamente, a guarda da Constituição, cabendo-Ihe: (...) III - julgar, mediante recurso extraordinário, as causas decididas em única ou última instância, quando a decisão recorrida: a) contrariar dispositivo desta Constituição; b) declarar a inconstitucionalidade de tratado ou lei federal; c) julgar válida lei ou ato de governo local contestado em face desta Constituição; d) julgar válida lei local contestada em face de lei federal".

128 Práticas que ferem os princípios jurídicos da Constituição Federal de 1988. Uma vez que todos os brasileiros são considerados iguais, alegam que não deveria haver privilégios de um segmento da população em detrimento de outros. Assim as ações afirmativas são vistas como um privilégio pelos grupos contrários às políticas de ações afirmativas para negros. 
Após analisar os argumentos de raça, cultura e econômico na passeata Marcha Zumbi dos Palmares, observa-se que os dois últimos se ressignificaram, transformando-se no argumento de classe social. O argumento de raça na Marcha Zumbi dos Palmares apareceu como o fator que explica a desigualdade entre não brancos e brancos. Ele foi associado à desigualdade fenotípica, que contribui para a existência do preconceito de marca discutido no Seminário em Brasília. No entanto, o discurso de raça sofreu mutação ao logo do tempo e apareceu na Conferência de Durban com um viés geneticista.

$\mathrm{Na}$ Conferência de Durban predominou a linha argumentativa que entende o problema da desigualdade brasileira como econômico, e não racial (SOUZA, 2005).

$O$ argumento da genética enfatizado por Sergio Danilo Pena aponta que todos os brasileiros têm no seu genoma a contribuição das raças: negra, indígena e europeia. Por isso não há como definir quem é negro no Brasil. O discurso da genética mantém o argumento de raça, só que passa a mencionar as diferenças de genes e não as diferenciações fenotípicas que prevaleceram na Marcha Zumbi dos Palmares.

É por este motivo que podemos confirmar a hipótese deste trabalho, de que $\mathrm{o}$ argumento de cultura e economia se imbricaram para formar o discurso de classe social, ao passo que o discurso de raça permaneceu com significado biológico no sentido genético, apesar de as teorias cientificas o terem desconstruído. O que indica a permanência (conceito raça) e a modificação (transformação do discurso econômico e cultural no de classe social) de certos argumentos das ações afirmativas na passagem do evento da Marcha de Zumbi dos Palmares à Conferência de Durban.

\section{REFERÊNCIAS BIBLIOGRÁFICAS}

ALMEIDA, Viritiana Aparecida de. Audiência Pública: Representação Social das políticas de ações afirmativas na Mídia Televisiva. 60 p. Monografia 
(graduação em ciências sociais) - Setor de Ciencias Humanas, Universidade Federal do Paraná, Curitiba, 2012.

ALVES, J. A. Lindgren. A Conferência de Durban contra o Racismo e a responsabilidade de todos. In: Revista Brasileira de Política Internacional (online). Vol. 45, no 2. pp. 198-223. Brasília: Instituto Brasileiro de Relações Internacionais, 2002. ISSN: 0034-7329. Disponível em:

<http://www.scielo.br/pdf/rbpi/v45n2/a09v45n2.pdf>, último acesso em 13/03/2013

BAUER, M.; GASKELL, G. (org). Pesquisa Qualitativa com texto, imagem e som: um manual prático. Tradução de Pedrinho Guareschi. Rio de Janeiro: Vozes, 2002.

BELLINTANI, Leila Pinheiro. Ação afirmativa e os princípios do direito: a questão das quotas raciais para ingresso no ensino superior no Brasil. Rio de Janeiro: Lumen Juris, 2006.

BOLTANSKI, Luc e CHIAPELLO, Ève. O novo espírito do capitalismo. São Paulo: WMF. 2009.

CAMPOS, Luiz Augusto; DAFLON, Verônica Toste; FERES JÚNIOR, João;;. Cotas no STF: Os argumentos como eles são. In: Revista Insight Inteligência. V. 49. Rio de Janeiro: [s.ed.], 2010. Disponível em: < http://gemaa.iesp.uerj.br/JFJ/wp-content/uploads/2011/05/Cotas-no-STF2010.pdf>, acesso em 18/03/2013.

COSTA, Sérgio. A mestiçagem e seus contrários: etnicidade e nacionalidade no Brasil contemporâneo. In: Tempo Social - Revista de Sociologia da USP. São Paulo: USP, 2001. Disponível em: < http://www.scielo.br/pdf/ts/v13n1/v13n1a10.pdf>, último acesso em 18/03/2013.

COSTA, Hilton; PINHEL, André; SILVEIRA, Marcos Silva da. (orgs.) Uma década de políticas afirmativas: panorama, argumentos e resultados. Ponta Grossa: Editora UEPG, 2012. ISBN 978-85-7798-148-9

DAMATTA, Roberto. Relativizando: Uma introdução a antropologia social. Petrópoles: Vozes, 1981.

EDUCRAFO - Educação e Cidadania de Afrodescendentes e Carentes. Exclusão no Brasil e fenótipo: Como mudar? (texto de apoio usado em 2003 pelos núcleos da EDUCAFRO). São Paulo: Franciscanos, [s.d.]. Disponível em http://mariadenazare.org.br.dish4167.net.ibizdns.com/educafro/Exclusao_no_Brasi I_e_fenotipo.pdf>, último acesso em 25/03/2013 
FERNANDES, Florestan. A integração do negro na sociedade de classes. $5^{\text {a }}$ Ed. Vol. I e II. São Paulo: Globo, 2008.

GRIN, Monica. A celebração oficial da nova diversidade no Brasil. In: Revista USP, n.68, p. 36-45, dezembro/fevereiro 2005-2006. São Paulo: USP, 2006. Disponível em < http://www.usp.br/revistausp/68/04-monica-grin.pdf>, último acesso em 19/03/2013

Este ainda obscuro objeto de desejo: políticas de ação afirmativa e ajustes normativos. In: Revista Novos Estudos. V. 59. São Paulo: CEBRAP, 2001.

GUIMARÃES, Antonio Sérgio Alfredo. A questão racial na política brasileira: os últimos quinze anos. In: Tempo Social - Revista de Sociologia da USP. São Paulo: USP, 2001. Disponível em: < http://www.scielo.br/pdf/ts/v13n2/v13n2a07.pdf>, acesso em 18/06/2012.

MOEHLECKE, Sabrina. Ação Afirmativa: História e Debates no Brasil. In: Cadernos de Pesquisa. № 117, p. 197-218. São Paulo: FGV, 2003. Disponível em: < http://www.scielo.br/scielo.php?script=sci_arttext\&pid=S0100$15742002000300010>$, acesso em 19/06/2012.

MOYA, Thais Santos; SILVÉRIO, Valter Roberto. Ação afirmativa e raça no Brasil contemporâneo: um debate sobre a redefinição simbólica da nação. In: Revista Sociedade e Cultura. V. 12. n. 2. [s.I.]: UFG, 2009. ISSN: 1980-8194. Disponível em: < http://www.revistas.ufg.br/index.php/fchf/article/view/9097/6271 >, acesso em 20/06/2012.

NASCIMENTO, Alexandre. Das ações afirmativas dos movimentos sociais às políticas públicas de ação afirmativa: o movimento dos cursos pré-vestibulares populares. In:II SEMINÁRIO NACIONAL MOVIMENTOS SOCIAIS, PARTICIPAÇÃO E DEMOCRACIA, Florianópolis, 2007. Anais do II Seminário Nacional Movimento Sociais, Participação e Democracia. Florianópolis: UFSC, 2007. ISSN 1982-4602 Disponível em: < http://www.sociologia.ufsc.br/npms/alexandre_do_nascimento.pdf>, último acesso em 18/06/2012

ROCHA, Neli Gomes da. Relações raciais e direito de visibilidade. Políticas públicas para diversidade na mídia. 74 p. Monografia (Graduação em Ciências Sociais) - Setor de Ciências Humanas, Universidade Federal do Paraná, Curitiba, 2009.

SOUZA, Jessé. Democracia racial e multiculturalismo: ambivalente singularidade cultural brasileira. In: Estudos Afro-Asiáticos, v. 38. Rio de Janeiro: Editora UCAM, [s.d.]. ISSN 0101-546X. Disponível em: < 
http://www.scielo.br/scielo.php?script=sci_arttext\&pid=S0101546X2000000200007>, acesso em 20/06/2012. 